\title{
Family and the Sexual Identity Development of Youth: A Comparative Sociological Study of the Semi-urban and Rural Youth in Ratnapura District of Sri Lanka
}

Welgamage Medhana Jayaprasad Welgama

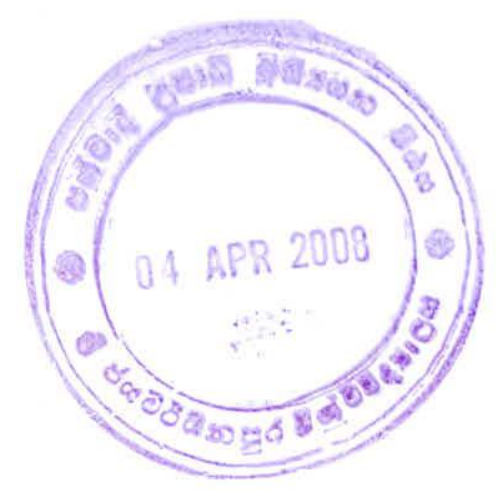

Master of Arts 
Family and the Sexual Identity Development of Youth: A Comparative Sociological Study of the Semi-urban and Rural Youth in Ratnapura District of Sri Lanka

Welgamage Medhana Jayaprasad Welgama

Thesis submitted to the University of Jayewardenepura for the award of the Degree of Master of Arts in Sociology June 2007 
Candidate's Declaration

The work described in this thesis was carried out by me under the supervision of Dr.Yasanjalee Jayathilake and a report on this has not been submitted in whole or in part to any university or any other institution for another Degree/Diploma.

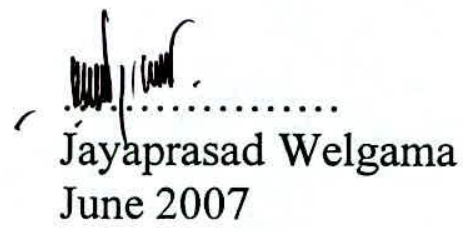




\section{Supervisor's Certification}

This thesis which is produced by WMJ Welgama(GS/SS/1561/2002), as a requisite of the Masters Degree in Sociology has been completed under the supervision of me. I hereby certify that this research is an independent work of him and that this thesis meets the required standard.

Fasarklayatillete.

Dr. Yasanjalee Jayathilake

Senior Lecturer

Department of Sociology and Anthropology

University of Sri Jayawardenapura.

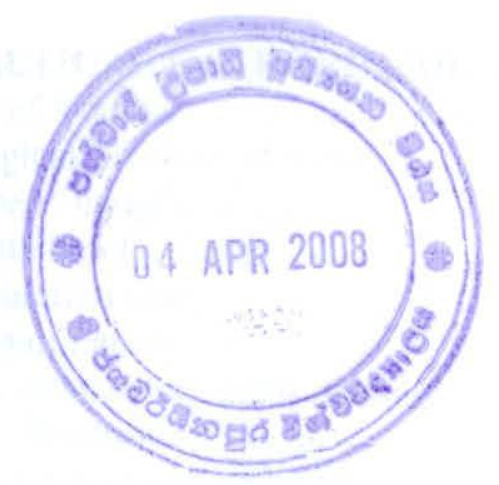




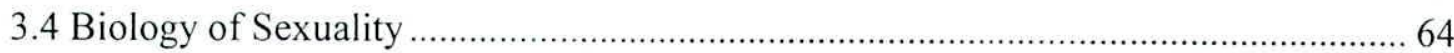

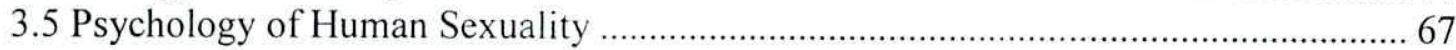

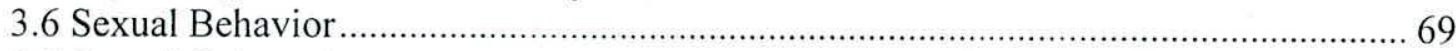

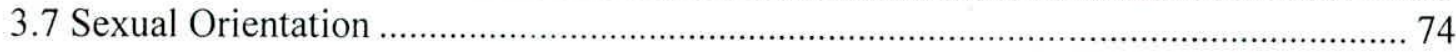

\section{Chapter Four}

4. FAMILY, YOUTH AND THE SEXUAL IDENTITY DEVELOPMENT ............. 82

4.1 Family, Urban -Rural Disparity and Sexual Identity ................................................ 83

4.2 Social Class, Family and the Sexual Identity ............................................................ 118

4.3 Family, Style of Parenting and the Sexual Identity .................................................. 121

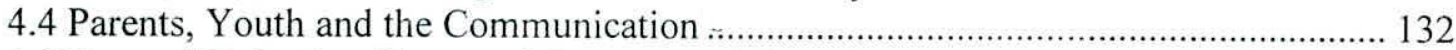

4.5 Parental Behavior, Structural Reasons and Sexual Identity ..................................... 135

4.6 Siblings and the Sexual Identity Development......................................................... 141

\section{Chapter Five}

5. FAMILY AND THE NEGATIVE SEXUAL IDENTITIES ............................... 147

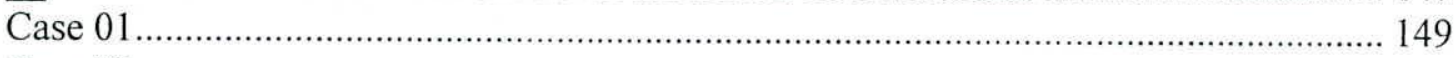

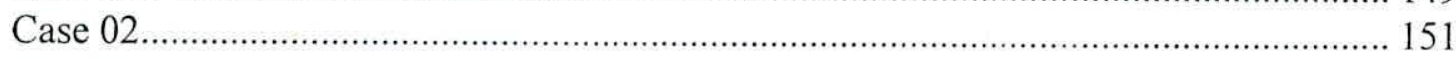

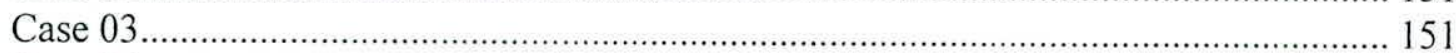

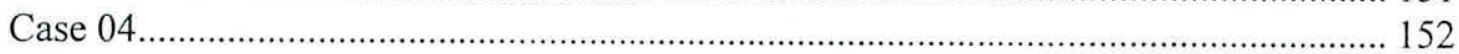

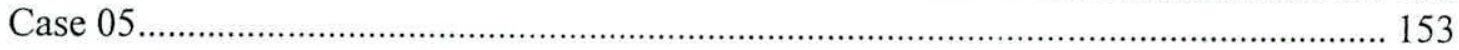

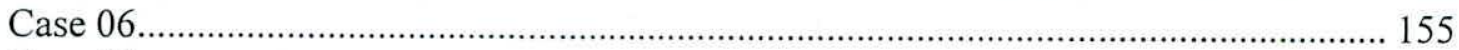

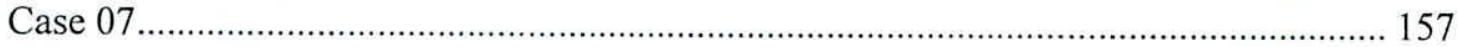

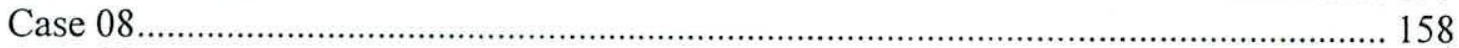

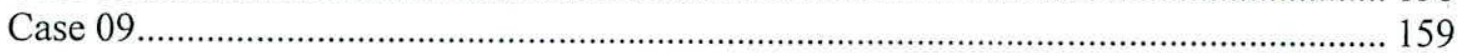

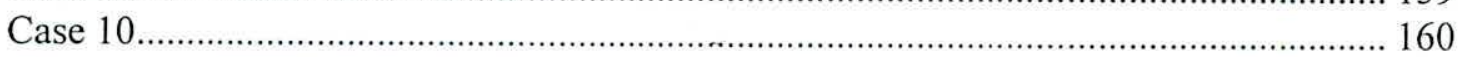

\section{Chapter Six}

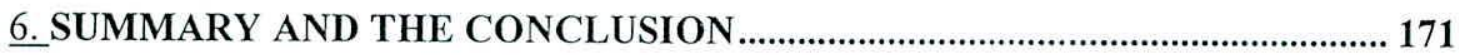

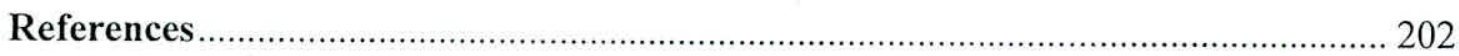

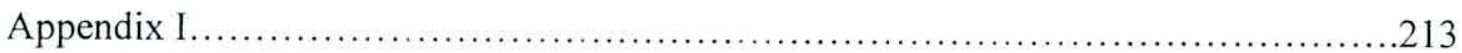




\section{List of Graphs}

$\begin{array}{lll}\text { Graph No } 01 \text { Education as a whole } & 87\end{array}$

Graph No 02 Education- Urban sector $\quad 88$

Graph No 03 Education- Rural sector youth 88

Graph No 04 Fathers' education by sector- Urban 88

Graph No 05 Father's education by sector-Rural $\quad 88$

Graph No 06 Mothers' education by sector-Urban $\quad 89$

Graph No 07 Mothers' education by sector- Rural $\quad 89$

Graph No 08 Gender role adherence by sector- Urban 90

Graph No 09 Gender role adherence by sector- Rural 90

Graph No 10 Number of hours watching TV by sector-Urban 92

Graph No 11 No of hours watching TV by sector - Rural 92

Graph No.12 Favorite TV channel by sector-Urban 92

Graph No 13 Favorite TV channel by sector-Rural 92

$\begin{array}{ll}\text { Graph No } 14 & \text { Expected level of discipline and obedience to mother by } \\ \text { Sector-Urban } & 96\end{array}$

Graph No 15 Expected level of discipline and obedience to mother by sector-Rural 96

Graph No 16 Expected levels of discipline and obedience to father by sector-Urban 96

Graph No 17 Expected level of discipline and obedience to father by sector-Rural $\quad 96$

Graph No 18 Attitude towards homosexuality and Youth who are expected high $\begin{array}{ll}\text { level of discipline by mothers } & 97\end{array}$

Graph No 19 Whether in a love affair or not by sector-Urban 99 
Graph No 20 Whether in a love affair or not by sector-Rural

Graph No 21 Number of romantic affair had by sector-Urban

Graph No 22 Number of romantic affair had by sector-Rural

Graph No 23 Duration of romantic affairs by sector - Urban

Graph No 24 Duration of romantic affairs by sector - Rural

Graph No 25 Attitude towards premarital sex by sector-Urban

Graph No 26 Attitude towards premarital sex by sector-Rural

Graph No 27 Sexually abused as a child by sector - Urban

Graph No 28 Sexually abused as a child by sector-Rural

Graph No 29 Witnessed sexual behavior by sector-Urban

Graph No 30 Witnessed sexual behavior by sector-Rural

Graph No 31 Sex lives of parents as mentioned by youth - Urban

Graph No 32 Sex lives of parents as mentioned by youth -Rural

Graph No 33 Male youth sexual orientation by sector

Graph No 34 Female sexual orientation by sector

Graph No 35 Level of freedom enjoyed in the home-Urban youth

Graph No 36 Level of freedom enjoyed in the home - Rural youth

Graph No37 Parent youth communication in regard to the choice of life partners by sector

Graph No38 Parent-Youth communication with regards to sexuality by sector

Graph No 39 Youth did both masculine and feminine domestic work by family Income 
Graph No 40 Positive or negative sexual identity of male youth and the level of intimacy with parents

Graph No 41 Positive or negative sexual identity of female youth and the level of intimacy with parents

Graph No 42 Positive or negative sexual identity of male youth and the level of individual freedom enjoyed within family

Graph No 43 Positive or negative sexual identity of female youth and the level of individual freedom within family

Graph No 44 Positive or negative sexual identity of male youth and the expected level of discipline within the family

Graph No 45 Positive, negative or unresolved sexual identities of female youth and level of discipline expected within the family

Graph No 46 High parental demands on discipline and their attitude towards premarital sex.

Graph No 47 Self control against unprotected sex and youth experienced high parental demand on discipline.

Graph No 48 Level of anxiety reported after sexual behavior and the amount of individual freedom enjoyed at home

Graph No 49 Number of sex partners had and the level of individual freedom enjoyed at home

Graph No 50 How often do youth communicate the matters of marriage partner selection with parents

Graph No 51 Youth and the intensity of communicating sexual matters with parents

Graph No 52 Positive or negative sexual identity of male youth and the level of religiosity of the family 
Graph No 53 Youth performance of gender related domestic roles and the percentage that are emotionally sensitive

Graph No 54 Gender based domestic role adherence of youth and attitude towards homosexuality

Graph No 55 Percentage of youth communicating sexual matters with siblings

Graph No 56 Percentage of youth communicating about marriage partners with siblings

Graph No 57 Percentages of male and female youth who communicate sexual matters with siblings

Graph No 58 How far satisfied with the advice extended by siblings in relation to marriage and sexuality

Graph No 59 Youth attitudes towards the stability of sex life of their siblings 
List of Tables

Table No.01 Mean Age at Marriage by Sex (1901-1994)

Table No 02 Reported Cases of Vice-Sri Lanka- 1998

Table No 03 Favorite Radio Station and Desired Level of Freedom in Selecting a Partner

Table No 04 Urban and Rural Youth Engaged in Different Sexual Behaviors by Gender

Table No. 05 Frequency of Youth Reported Parental demand On the Discipline in Home and levels of Sexual Communication with Parents

Table No. 06 Frequency of Youth Reported Parental demand on the Discipline in Home and levels of Sexual Communication with Parents 


\section{Acknowledgements}

First, I wish to thank my supervisor Dr. Yasanjalee Jayathilake at the University of Sri Jayewardenapura for the intellectual guidance extended. I thankfully remind Professor Tennyson Perera with whom I initially discussed the study related concepts and theory which were extremely useful. I should extend my thanks to Professor David Silverman at Goldsmiths College, London and Professor Joe Weeramunda, Department of Sociology, University of Colombo for their views. I express my gratitude to Mrs Swarna Rupasinge, the Director of Youth Services, Ratnapura branch, Mr. Bimal Rajakaruna, former youth counselor of the National Youth Council and Mr. E. Dayarathna, the youth services officer of Ratnapura Divisional Secretariat for their assistance for reference and field work. My sincere thanks go out to Mrs. Susila Beyetris Kamalawathi, the Gramaniladari of Mihindugama who helped me developing rapport with the youth. I am indebted to Mr. Sanduan Sameera, the youth leader who helped me in the field. I am grateful to Mr.Nirohan Withanage, lecturer in Statistics at the Department of Social Sciences for his support at the data analysis. It is my pleasure to thank Mr. Sunil Shantha, Head of the Department of Social Sciences for all understanding unless this exercise would not have been practical. Mr. Saman Handaragama of the Department of Social Sciences deserves thanks for his useful comments. I sincerely thank Mrs. Dammika Kumari Dharmadasa, Mr. Ravindra Bandara, Mr. Ranjula Dayananda and Mr. Wimalasena Bandara for their support. Finally I would like to thank Priyanthi for her tolerance and commitment. 


\title{
Family and the Sexual Identity Development of Youth: A Comparative Sociological Study of the Semi-urban and Rural Youth in Ratnapura District of Sri Lanka
}

\author{
Welgamage Medhana Jayaprasad Welgama
}

\begin{abstract}
The thesis presents a sociological analysis on family and the sexual identity development of semi-urban and rural youth in Sri Lanka. The basic research problem stems from the social milieu where Sri Lankan families are adapting the socialization process following the demands of global age. The study was carried out in the Ratnapura District of the Sabaragamuwa Province.

The focus of the study is to capture the functionality of the structured relationships within the family as it becomes the primary context of the sexual identity development of youth. Parent- child relationship and the inter-sibling relations are evaluated for the potential of shaping sexual self of the youth. In this context, special attention is drawn to the difference between semi- urban and rural family in regard to the sexual identity development and the family backgrounds that are responsible for the development of positive and negative sexual identities too are considered.

In addition to the above aims, the present study highlights the inherent complexity of the concept of sexual identity. In the process of conceptualizing sexual identity, the study examines historical and cross cultural expression of sexual identities. The study emphasizes the social construction of sexuality with the support of existing literature.
\end{abstract}

For this study, both quantitative and qualitative approaches were used. The sample represents semi- urban and rural youth $(n=225)$ selected employing the techique of simple random sampling. Postal survey and the informal interview methods were adopted. Qualitative data were collected from ten case studies of youth whose family backgrounds have confused their sexual identities.

The study reveals the fact that the semi-urban and rural families do not drastically contrast with each other, they constitute two different contexts of sexual identity 
development through subtle avenues of diversified interaction within the family. However the study proves that the social class of family is not correlated with any form of sexual identity. Semi-urban and rural difference pertaining to the sexual identity development is a result of diverse factors like gender role socialization, style of parenting and the degree of openness to the external influence. Further, the study captures how the different expressions of sexual identity vary on the basis of semi- urban and rural differences. Apart from that the study discloses low prevalence of sexuality related communication between parents and youth that results in the development of sexual identity either negative or positive side. Sibling-sibling relations are divulged to be less influential on sexual identity development. The qualitative analysis unveils a number of risk factors within the family that can be treated as the precursors of negative sexual identity development. Furthermore, the thesis argues that the Sri Lankan family leaves a little margin for the negative or unresolved sexual identities and it remains emotionally less supportive in case of negative sexual identities. 


\section{Chapter One}

\section{Introduction}

\subsection{Background of the Study}

This research is both quantitative and qualitative sociological study, which focuses the family role in the sexual identity development of Sri Lankan youth. A comparative analysis of the identity development of urban and rural youth is highlighted. Added to its biological and chronological dimensions, youth is a socially constructed phenomenon, which is discussed in the sociology of age and status. Each society has a different 'social age clock' by which individuals at different age groups are socially assigned different roles and statuses (Kroger 2000 , p.46). In that sense the age related status might significantly vary in the cross-cultural experience. This study will be a novel experience as it may address the unique socio-cultural and economic background in which the Sri Lankan family constructs the youth sexual identities.

Generally, youth is accepted as the golden age of the human life cycle. Relative absence of morbidity being in the peak of physical vigor, specific psychological traits add more color to the youth who are at the threshold of maturity. Youth is considered to be the most progressive social category. Trotsky equated this specific age group to the thermometer of society (Survey Report on Youth Needs and Attitudes-National Youth Council 1983). This suggests that youth are the first to react being in the social forefronts. All these make youth an attractive material for research. 
Sociology may provide formidable tools of analysis since the concept of youth is largely a social construction. The timing of Sri Lankan youth and the expected role of youth may show certain uniqueness as they are in a multicultural social milieu which is subjected to the currents of global change.

Despite of the romanticization, historically youth has been perceived as a problematic age of the human life cycle. The famous Greek philosophers Socrates and Plato had documented the restless attributes of the youth (Dacey \& Travers 1996, p.262). The modern invention of the adolescence in 1880's by G.H Stanley Hall highlighted it as a period of 'storm and stress', which strikes the individual at the onset of youthful behavior. More often the available academic literatures go with the assumption that youth is problematic (Kuper \& Kuper 1996, p.4). Many perspectives on the human development in biological, psychological and sociological orientations (Biopsychosocial Model), explain youth to be one of the most turbulent periods of human life cycle.

Is youth problematic? Concepts of 'identity' and 'identity crisis' coined by Erik Erickson adequately provide a formidable explanation regarding the psychosocial uncertainties of adolescence and youth (cited in Collins \& Coltrane 1991). As explained in the Encyclopedia of Social and Cultural Antropology, identity refers to one's 'properties of uniqueness and individuality', which makes him or her distinct from all others. At the same time identity may show the 'qualities of sameness', which provides the individual with the power to be associated by the other groups (Barnard \& Jonathan 1996, p.292). In that sense, identity is the uniqueness of one's self with reference to the larger social body he or she is linked. One's personal identity is a collective reflection of 'personal traits, physical attributes 